\title{
Identifying Factors That Impact Virtual Teams
}

\author{
Matilda Isaac Mustapha \\ Madonna University \\ Assistant Professor
}

\begin{abstract}
In our modern age of globalization, organizations are forced to explore several means of increasing performance, by using technology in the most efficient ways. The speed and agility of technology have caused the materialization of Virtual Teams. The following literature review attempts to cover various identifying factors that impact virtual teams. Factors such as Leadership and Management Styles, Multiculturalism, Communication, Conflict resolution, and Trust. Studies showed that effective leadership would help to facilitate an easier workflow. This included leaders that understood the significant effects of multiculturalism on team cohesiveness. The literature gives a clear understanding of how communication if not properly managed can lead to conflict in virtual teams. The literature reported on the investigation of the impact of conflict resolution on virtual teams and how trust must be built to encourage high work performance. Though several studies on the dynamic nature of virtual teams were insightful, many contained limited solution on conflict resolution. This study concludes with the possibility of future investigation and hopes that more studies would soon emerge.
\end{abstract}

KeyWords: Conflict Resolution, Virtual Teams, Multiculturalism, Cross Cultural Teams.

\section{INTRODUCTION}

Crossing through regional boundaries is the phenomenon known as Virtual teams. These are teams that are created either for short-term projects or long-term projects. Huang [1] opined that $50 \%$ of companies with larger than 5,000 employees use virtual teams. These were teams that were believed to have a long-standing history of co-ordination routine. These comprised of highly skilled personnel who were specialized in different areas and had being brought together via technology for a common goal. While the advantages of the virtual teams are of efficiency and speedy production, it is equally important for an organization to identify the different factors that impact the performance of such teams (Bergiel, B, Belgiel E, \& Balsmiere [2]. These include and the effect of leadership style and management qualities, the role of multiculturalism on team synergy, how communication affects team performance, the impact of conflict resolution on team members and trust and awareness among virtual team members. Huang [1] suggested that unlike face to face teams, virtual teams lacked the personal touch that might bring about trust. Managers are expected to be first respondents in such teams and their ability to transform the team is very important. To compete in a fast-paced economy, many companies have resorted to using this medium because it incorporates the new wave of technology with physiological aspects of work processes and functionality. Teams were gathered together across geographical, regional, national, culture, language, and time. This too can create a more pronounced cultural diversity and multiculturalism that affects communication and therefore performance. When communication lines become blurred, an organization must determine the most skillful way to resolve this problem and bring trust back into the team. 


\section{Leadership and Management of virtual teams}

A recent study by Huang [1] showed that trust was a key factor in team motivation. Trust worthy leaders often were the leaders who had the ability to perform the task with integrity and were able to maintain a friendship environment. The transformational leader often excelled in such environment because they knew how to integrate workers and properly share the goals and objectives of the organization. According to Bergiel, et al. [2], strong leadership was important in virtual teams because a leader had to be focused, determined and trustworthy. Henry \& Hartzler [3] opined that a leader must have the ability to understand the team and have knowledge in the task and activities of the team. A manager must not accept incompetence and poor output. Such behaviors must be addressed, and plausible causes must be investigated. A leader must be able to maintain a proper monitoring and periodic evaluation of team members. Furthermore, a leader must have the ability to create a forum for the unification of ideas and just like a face to face team the goals must be specific, measurable, achievable, relevant and timely. It is stated in the article by Horwitz \& Bravington [4], that leading virtual teams can pose several difficulties, but as the team progresses and mature a leader must be capable of transitioning from an advocate to a catalyst and then to an integrator. A leader should have great knowledge of the subject matter, and they must make sure that the necessary tools for performance are available to the team. Leaders should also develop habits that go with a great value system. Evans \& Lindsey [5] intimated that leadership that fostered legal and ethical behaviors and place emphasis on management and fiscal accountability are, more likely than not to attract followers that will embrace their ideas. One of the challenges of leadership is developing the appropriate recruiting and selection methods for virtual teams [4]

\section{The impact of multiculturalism on Virtual teams}

As leaders strive to enhance team performance, they are often faced with the role of multiculturalism that exist within virtual teams. The fact that technology is used to connect people from different parts of the world creates a possibility that teams will be culturally diverse. [6] Such cultural diversity includes norms, values, perception and cognitiveness [7] in the study of the effects of cultural diversity on work teams by Staples \& Zhao [6] the effect of cultural diversity was compared to face to face teams using heterogeneous groups. The study concluded found that heterogeneous groups were less satisfied and more cohesive and had more conflict than homogeneous groups. Whereas in face to face teams homogenous groups performed better. The paradox of being more cohesive yet less satisfied was buttressed by Glikson \& Erez [7], in their article "Emotional display norms in virtual teams" The article stated that negative emotions in heterogeneous teams were often repressed due to different cultural norms while positive emotions were often expressed. Furthermore often a misinterpretation of norms as a result of diversity was a matter of concern. An international venture survey, where French managers were asked to comment on Americans gave an interesting feedback. Their responses showed that often time's norms were misinterpreted as being difficult, and not welcoming of the ideas of others.[8] It was noted that workers who possessed a high measure of global identity demonstrated greater agreement on display norms for multiculturalism.

\section{The impact of communication on virtual teams}

While some have argued that virtual teams enable an organization to achieve faster time for producing rapid work, with processes integration despite the geographical difference; others believed that there are some inherent factors that can negatively impact the team performance [4]. In the article by Jang [9], the facilitation of trust in teams was crucial to effective communication. The concluded that the more team members communicated, the greater the team awareness and the perceived interdependence and the greater the level of trust. In face to face teams, location is a common denominator. Shared language and culture can minimize the 
effects of misunderstanding. Virtual teams were noted to be agile in the dissemination of information because it was invisible. However, the lack of physical contribution may lead to awareness factors such as informal encounters and therefore spontaneous connection becomes absent. This attribute when present in face to face teams allows for the proper dissemination of information and easy workflow [10]. It is important to employ several strategies at the crucial stages of team development to enhance communication. Further consideration was given to the developmental phase of virtual teams. The reason was that the formation stages of the team would set the tone for the subsequent stages: Bergiel et al. [2] gave the following possible recommendation to maximize the effects of communication on virtual teams;

1. Moving to electronic communication after a face to face meeting might help.

2. Objective must be clear and easy to implement

3. Allow members to become acquainted

4. Make sure the tools necessary for production are available

5. Maintaining a consistency on how agreements are made is also relevant

It is significantly noted that there are many idiosyncrasies that are prevalent in different cultures. This is why a clear means of communication is necessary. What one person thinks is a norm might not be suitable for a team where diversity exists. The technology used should include voice projection and visuals such as video conferences. This could add a personal touch to the team. [2]

Many researchers believed that it is important for an organization to align different task with different technological functions order to obtain performance efficiency and this was parallel to the idea that coordinating different task to applicable virtual teams. Not every team will perform well under the same conditions [10]

\section{Dealing with Conflict Resolution in virtual teams}

The expectations of virtual team members across different time zones and the crossing of those zones can be quite a hassle. Language barriers can pose a big threat because more often multicultural teams experience a gap in understanding. Different culture has their individual norms, and these norms are what makes up their identity. When their values are no longer aligned with their external environment, it creates total misunderstanding. A gap in understanding can generate conflict or disagreement within work teams. Conflict resolution, therefore, is the ability to effectively manage these disagreements [2]. Managing might not be easily realized due to the lack of face to face contact because they might not be notable until a member.

Vocalizes these concerns. In the study "Getting it together: Temporal coordination and conflict management in global virtual teams," they found that the ways virtual teams manage conflict was significant to their performance. The fact that virtual teams lacked all the cues of a traditional team it was important to have a mechanism in place to manage conflicts [11]. Pazos, Ustun \& DelAguila [12] contended that conflict management moderated the relationship between team commitment and goal outcome. They found that high level of goal commitment proved to be beneficial to the overall team performance. In other cases, temporal coordination was viewed as more suitable for mitigating virtual team conflict. Avoidance was found to be detrimental to virtual team performance. By avoidance, it meant a member would not want to confront another and as such prolonging the process of resolution. Further analysis proved that a more cohesive structure that encouraged the cycling of work between team members and the continuous flow of information on decisions made created a more synergetic environment for the virtual team [10]. This brings one to the notion of human emotions when 
dealing with virtual teams. The fact that people are not in physical contact does not mean that their work is emotionless. A partner can be unresponsive due to unresolved issues thereby hindering the process for another member of the same team. It is also believed that accountability can be a great way to amend the situation by making sure that members are forced to interact in a loop, and each one in the loop was responsible for the others.

\section{Trust and Awareness within virtual teams}

Human nature is one that is in a constant conflict with its values and beliefs. There is the need for affiliation which cannot be negated by the need for uniqueness. Rather these two psychological aspects of our lives must complement each other [8]. It was found that in virtual teams trust must be present for the success of performance measures. The more a team communicated, the greater the team awareness of who its members were and the values that they might share in common. This is a prerequisite for interdependence and a catalyst for trust [9]. Trust can be realized in different forms. It could be trusted for team members; it could be trusted for organizations goals and trust for leadership. A leader that is transparent and possess the power to motivate and empower their members to build trust in their teams, and it is with this they can effectively move the team through different phases of their projects. When there is trust, there is respect for values and consideration for others. The misunderstanding that is prevalent in multiculturalism will be alleviated when team's members trust the shared ideas of their counterparts. Researchers contend that it is important not to be too judgmental of others but to be more understanding of our differences and uniqueness [13]. Some researchers proposed recommendations that included; making sure leaders enlist the help of experts who specialize in team development. A complete cultural identity profile is important because it allows virtual team members into the lives of their colleagues and partners all over the globe. An article by King [14] touched on the power of intent to create a trustworthy environment. The onus is on leaders to investigate their virtual communication teams to see what level of trust exist within them. It is equally as important to galvanize the team and develop programs that would

Encourage trust. This is the only way proper communication can exist, thereby increasing performance levels.

\section{CONCLUSION}

The literature review has established a series of facts on the factors that impact virtually teams and each of these is equally important, however, communication is the key to information and how work processes can proceed without the impact of the other factors reviewed. Other factors such as leadership management, trust, multiculturalism, conflict resolution are centered in the fabric of communication. We established that virtual teams are teams that comprises not only of individuals from all aspects of life but also from different geographical regions and cultural backgrounds. The fact that their location is different in itself poses a threat to synergy. As opposed to face to face teams, virtual teams lack the ability to have a fair judgment of their fellow team members and lack the human aspect of a traditional work life. We must keep in mind that because there is no personal touch does not mean that they are emotionless. Very often the virtual team is treated as an automated, and this might be the reason such teams might harbor conflict for a considerable amount of time. Conflict vary in forms such as work habits and not necessary goal conflict. Some researcher observing virtual teams had noticed that while the team members had a different way to reach a goal they somehow get a common sense of accomplishment when the goals were achieved. It is important to note that issue will arise even in a face to face team, leaders play a significant role in how such issues are managed. The leaders who adopt the transformation style of leadership are effective in redirecting the team to the goals and objectives of the projects. They are often 
motivational and have the capability to not only advocate but also integrate the teams for better performance. The leaders must be trust worthy and understand how to influence the team to adopt a trust mantra. When communication is broken, people tend to withdraw into a more non-responsive mode because trust is then perceived as unachievable. A leader must investigate the differences between team members such as cultural differences in beliefs and core values. This can be a major problem if members of the virtual team feel that they are being disrespected. Many people, rather than try to understand others, they might judge by their ignorance. Virtual teams should effectively use technological means such as audio and video conferences to add some human aspects to the work process. Furthermore, diversity in teams is very effective because its evidence of a collaboration of people from all works of life with varying skill that if correctly aligned with the right task can produce a level of high performance. Finally, the factors that impact virtual teams, if properly managed can produce a high level of performance which will give rise to a competitive advantage in this rapid global economy.

\section{FURTHER RESEARCH}

1. Further investigation can yield more insight into the different types of technology and how virtual teams adapt to change in technology.

2. The impact of Conflict resolution can be explored me more details to determine what types of management style can limit such conflict and steps to managing them.

3. The human aspect of virtual teams and how to incorporate that into the work process, by creating awareness.

4. Building trust where there is value conflict or cultural dissonance.

\section{Reference}

Huang, M. (2010). Behavior, trust and leader emergence in virtual teams. (Order No. 3467235, Stevens Institute of Technology). ProQuest Dissertations and Theses, , 124-n/a. Retrieved

http://ezproxy.emich.edu/login?url=http://search.proquest.com/docview/884349260?accountid=10650. (884349260).

Bergiel, B. J., Bergiel, E. B., \& Balsmeier, P. W. (2008). Nature of virtual teams: A summary of their advantages and disadvantages. Management Research News, 31(2), 99-110. doi:http://dx.doi.org/10.1108/01409170810846821

Henry, J. E., \& Hartzler, M. (1997). Virtual teams: Today's reality, today's challange. Quality Progress, 30(5), 108109. Retrieved from

http://ezproxy.emich.edu/login?url=http://search.proquest.com/docview/214519830?accountid=10650

Horwitz, F. M., Bravington, D., \& Silvis, U. (2006). The promise of virtual teams: Identifying key factors in effectiveness and failure. Journal of European Industrial Training, 30(6), 472-494.

doi:http://dx.doi.org/10.1108/03090590610688843

Evans R. J \& Lindsey, N, W (Eds.) (2005). The management and Control of quality. Thompson: Southwestern (6th Ed).

Staples, D. S., \& Zhao, L. (2006). The effects of cultural diversity in virtual teams versus face-to-face teams. Group Decision and Negotiation, 15(4), 389-406. doi:http://dx.doi.org/10.1007/s10726-006-9042-x

Glikson, E., \& Erez, M. (2013). Emotion display norms in virtual teams. Journal of Personnel Psychology, 12(1), 2232. doi:http://dx.doi.org/10.1027/1866-5888/a000078

Solomon, M, R. (2013). Consumer Behavior Buying, Having and Being. Manchester: Pearson

Jang, C. (2009). Facilitating trust in virtual teams: The role of awareness. Competition Forum, 7 (2), $399-407$.

Retrieved from

http://ezproxy.emich.edu/login?url=http://search.proquest.com/docview/214846013?accountid=10650 
Prachyl, C., Quintanilla, H., \& Gutiérrez, L. A. (2011). Managing international consulting projects and international business courses using virtual teams. Journal of Instructional Pedagogies, 5, 1-9. Retrieved from http://ezproxy.emich.edu/login?url=http://search.proquest.com/docview/863850361?accountid=10650

Montoya-Weiss, M., Massey, A. P., \& Song, M. (2001). Getting it together: Temporal coordination and conflict management in global virtual teams. Academy of Management Journal, 44(6), 1251-1262. Retrieved from http://ezproxy.emich.edu/login?url=http://search.proquest.com/docview/199776908?accountid=10650

Jackson, M. (2002), "Private lives in the internet era: the impact of technology on workers' homes", Perspectives on Work, Vol. 6 No. 2, pp. 12-14.

Pazos, P., Ustun, A., \& DelAguila, R. (2011). The role of conflict management on virtual team

Performance and Satisfaction. IIE Annual Conference. Proceedings, , 1-10. Retrieved from

http://ezproxy.emich.edu/login?url=http://search.proquest.com/docview/1190347413?accountid=10650

Mancini, D. J. (2010). Building organizational trust in virtual teams. Journal of Behavioral Studies in Business, 2, 1-5. Retrieved from

http://ezproxy.emich.edu/login?url=http://search.proquest.com/docview/760872429?accountid=10650

King, C. (2007). Building trust in global virtual teams: An innovative training model. Training \& Management Development Methods, 21(3), 315-320. Retrieved from

http://ezproxy.emich.edu/login?url=http://search.proquest.com/docview/202605842?accountid=10650 